\title{
Analisis Pengaruh Strategi Knowledge Management Terhadap Efisiensi Kerja Karyawan
}

\author{
Gaby Novryma Pakiding *1, Augie David Manuputty, S.Kom., M.Cs ${ }^{2}$ \\ ${ }^{1,2}$ Universitas Kristen Satya Wacana; J1. Diponegoro No.52-60, Salatiga, Kec. Sidorejo, Kota \\ Salatiga, Jawa Tengah 50711, (0298) 321212 \\ ${ }^{3}$ Jurusan Sistem Informasi, FTI UKSW, Salatiga \\ e-mail: *11 gabynovryma@gmail.com, ${ }^{2}$ augiemanuputty@gmail.com
}

\begin{abstract}
Abstrak
Penelitian ini bertujuan untuk mengetahui kondisi penerapan strategi knowledge management dan mengindentifikasi pengaruh knowledge management terhadap efisiensi kerja karyawan di PT. Asuransi Sinar Mas. Hal ini dikarenakan strategi manajemen pengetahuan atau knowledge management sudah sangat dibutuhkan oleh suatu perusahaan dalam meningkatkan keuntungan dan aset perusahaan, khususnya sumber daya manusia. Sebelum mengetahui seberapa berpengaruh knowledge management terhadap efisiensi kerja karyawan, maka terlebih dahulu perlu dilakukan pengujian terhadap kondisi penerapan strategi knowledge management yang sedang berjalan di perusahaan tersebut. Dalam penelitian ini penulis menggunakan metode kuantitatif dengan pengumpulan data yang disebarkan kepada 35 responden sebagai sampel untuk mendapatkan data primer. Kemudian untuk metode pengukuran penulis menggunakan skala likert dan penggabungan strategi knowledge management dengan faktor kualitas dari European Foundation for Quality Management (EFQM). Pada perhitungan skala likert dan didapatkan hasil 4,10 dimana dengan hasil tersebut keterangan yang didapatkan adalah baik, untuk pengujian kualitas penerapan knowledge management secara keseluruhan mendapatkan persentase $77,9 \%$ sehingga dapat dikatakan baik, lalu untuk tingkat pengaruh strategi knowledge management terhadap efisiensi kerja karyawan adalah 77,6\% atau dengan kata lain knowledge management berpengaruh terhadap efisiensi kerja karyawan. Walaupun angka yang didapatkan sudah cukup baik, namun masih perlu dilakukan peningkatan oleh perusahaan agar dapat bersaing dengan perusahan lain.
\end{abstract}

Kata kunci-Strategi Knowledge Management, Efisiensi Kerja, European Foundation for Quality Management (EFQM), Skala Likert

\begin{abstract}
This study aims to determine the conditions of the implementation of knowledge management strategies and identify the effect of knowledge management on employee work efficiency at PT. Asuransi Sinar Mas. Reason being that knowledge management strategy is very needed by a company to increase profits and company assets, especially human resources. Before knowing how much influence knowledge management has on the work efficiency of employees, it is first necessary to test the conditions of the implementation of knowledge management strategies that are being run in the company. In this study, the researcher used a quantitative method by collecting data distributed to 35 respondents as a sample to get primary data. Then for the measurement method, the researcher used a likert scale and merged knowledge management strategies with quality factors from the European Foundation for Quality Management (EFQM). From the likert scale calculation and the 4.10 results obtained
\end{abstract}


where this is considered good, to test the quality of the application of knowledge management as a whole a percentage of $77.9 \%$ was acquired where it can be said to be good, then for the level of influence of knowledge management strategies on employee work efficiency is $77.6 \%$ or in other words, knowledge management affects employee work efficiency. Although the figures obtained are good enough, there is still a need for the company to make improvements so it can compete with other companies.

Keywords - Knowledge Management Strategies, Work Efficiency, European Foundation for Quality Management (EFQM), Likert Scale

\section{PENDAHULUAN}

Knowledge Management (KM) atau manajemen pengetahuan adalah alat, teknik, strategi untuk menyimpan, menganalisis, mengorganisir, meningkatkan dan membagikan pengalaman bisnis [1]. Knowledge Management (KM) bukanlah hal yang lumrah bagi perusahaan di zaman sekarang ini. Knowledge Management dapat menjadi sebuah nilai tambah dan manfaat yang baik bagi perusahaan. Beberapa manfaat yang bisa didapatkan dari penerapan KM seperti meningkatkan pengambilan keputusan, meningkatkan efisiensi cara kerja dan proses, meningkatkan kemampuan dalam berinovasi, dan menghemat kebutuhan biaya dan waktu [2].

Manajemen pengetahuan terbagi menjadi dua, yaitu pengetahuan tacit dan pengetahuan eksplisit. Pengetahuan tacit adalah pengetahuan yang didapat individu dari pengalaman seharihari, yang pada dasarnya sulit untuk diduplikasikan dan diajarkan kepada orang lain. Kunci dari pengetahuan tacit adalah pengalaman. Maka dari itu, pengetahuan tacit bersifat personal, yang membuatnya sulit untuk dikomunikasikan dan diresmikan. Sedangkan, pengetahuan eksplisit adalah pengetahuan yang dapat ditransfer kepada individu lain sehingga dalam praktiknya mudah untuk dideskripsikan ke dalam dokumen, pelatihan, dan lain-lain dimana penulis mengkategorikan ke dalam bentuk prosedur kerja, dan teknologi [3].

PT Unilever Indonesia, PT United Tractor dan PT Telkom adalah sebagian contoh organisasi yang sudah berhasil mengelola knowledge management (KM) atau pengetahuan sumber daya manusia di dalamnya menjadi sebuah sistem yang bisa dijadikan pembelajaran bagi organisasi lainnya. Hal ini terlihat dari presentasi mereka dalam ajang pemanasan Indonesian Most Admired Knowlegde Enterprise (MAKE) di Jakarta 14 Maret 2012 [4].

Penelitian pada jurnal ini dilakukan di PT Asuransi Sinar Mas untuk mengetahui bagaimana peran knowledge management terhadap efisiensi kerja karyawan.

PT. Asuransi Sinar Mas (ASM) merupakan salah satu perusahaan asuransi umum terbesar di Indonesia. Visi Asuransi Sinar Mas adalah "Menjadi perusahaan asuransi profesional dan terpercaya dengan memberikan nilai yang berarti kepada nasabah, perusahaan reasuransi, agen, rekanan, pemegang saham dan karyawan kami." Untuk mencapai Visi tersebut Sinar Mas memiliki 4 Misi yaitu "Mengenal dan memenuhi kebutuhan nasabah; hasil underwriting yang menguntungkan; mengembangkan bakat, meningkatkan produktivitas dan efisiensi karyawan; serta Inovasi produk dan pengembangan teknologi informasi yang berkesinambungan" [5].

Salah satu misi dari PT Asuransi Sinar Mas yang membuat penulis tertarik untuk melakukan penelitian dengan judul "Pengaruh Strategi Knowledge Management terhadap Efisiensi Kerja Karyawan" adalah misi ketiga, "Mengembangkan bakat, meningkatkan produktivitas dan efisiensi karyawan". Penulis ingin melihat apakah terdapat pengaruh dari strategi knowledge management dalam efisiensi kerja karyawan PT. Asuransi Sinar Mas.

Untuk memfokuskan penelitian, penulis membuat rumusan masalah yaitu "Bagaimana Strategi Knowledge Management dapat berperan terhadap efisiensi kerja karyawan?" yang

Pakiding, et., al (Analisis Pengaruh Strategi Knowledge Management Terhadap Efisiensi Kerja Karyawan) 
kemudian akan dijawab oleh penulis pada hasil dan pembahasan. Tujuan penelitian yang ingin dicapai adalah untuk mengetahui kondisi penerapan strategi knowledge management yang berjalan pada perusahaan dan mengidentifikasi pengaruh strategi knowledge management terhadap efisiensi kerja karyawan. Manfaat penelitian yang ingin dicapai adalah memberikan pandangan berupa pengaruh knowledge management terhadap efisiensi kerja karyawan.

\section{METODE PENELITIAN}

\subsection{Kajian Pustaka}

\subsubsection{Knowlegde Management}

Seperti yang tertulis pada Latar Belakang Masalah, telah dijelaskan beberapa pengertian dan manfaat yang bisa didapatkan dari knowledge management.

Knowledge management atau manajemen pengetahuan terbagi menjadi 2, yaitu pengetahuan tacit dan pengetahuan eksplisit.

Tacit knowledge atau pengetahuan tacit adalah pengetahuan yang didapat individu dari pengalaman sehari-hari, yang pada dasarnya sulit untuk diduplikasikan dan diajarkan kepada orang lain. Kunci dari pengetahuan tacit adalah pengalaman. Maka dari itu, pengetahuan tacit bersifat personal, yang membuatnya sulit untuk dikomunikasikan dan diresmikan [3].

Menurut Polanyi dalam Nonaka (1994), pengetahuan tacit bersifat 1) tidak dapat dibagi 2) merupakan hal yang lebih banyak diketahui daripada disampaikan 3) seringkali terdiri dari kebiasaan-kebiasaan dan budaya yang tidak dapat ditentukan sendiri 4) tidak dapat dikodifikasikan, tapi hanya dapat dipindahkan atau diperoleh dari pengalaman 5) menggambarkan know what (fakta) dan know why (sains) 6) melibatkan pembelajaran dan skill 7) terbentuk dalam kelompok dan hubungan organisasional, nilai inti, asumsi-asumsi dan keyakinan, sulit diidentifikasikan, disimpan, dihitung dan dipetakan [6].

Explicit knowledge atau pengetahuan eksplisit adalah pengetahuan yang dapat ditransfer kepada individu lain sehingga dalam praktiknya mudah untuk dideskripsikan ke dalam dokumen, pelatihan, dan lain-lain dimana penulis mengkategorikan ke dalam bentuk prosedur kerja, dan manual guide [3].

Menurut Nonaka dan Takeuchi (1999:3), Explicit knowledge (documented, computer) readily accessible, as well as documented into formal knowledge resources that are often well organized. Pengetahuan eksplisit adalah pengetahuan yang siap diakses, telah didokumentasikan dalam sumber pengetahuan formal yang telah diorganisir dengan baik [6].

\subsubsection{Strategi Knowlegde Management}

Pada dasarnya strategi organisasi dalam knowledge management terbagi menjadi 2 jenis yaitu strategi kodifikasi (condifitcation strategy) dan strategi personalisasi (personalization strategy).

Strategi kodifikasi lebih fokus pada penyimpanan pengetahuan eksplisit . Strategi kodifikasi ini cocok untuk pemecahan masalah yang sifatnya sering terjadi berulang kali.

Jika pada strategi kodifikasi lebih fokus pada pengetahuan eksplisit, maka pada strategi personalisasi ini lebih fokus pada pengetahuan tacit. Pada strategi ini lebih menekankan pada komunikasi antar individu dan berbagi pengetahuan dengan konsultasi, diskusi, dan sebagainya.

\subsubsection{Efisiensi Kerja}

Efisiensi dalam Kamus Besar Bahasa Indonesia (KBBI) berarti:

1. ketepatan cara (usaha, kerja) dalam menjalankan sesuatu (dengan tidak membuang waktu, tenaga, biaya); kedayagunaan; ketepatgunaan; kesangkilan. 
2. kemampuan menjalankan tugas dengan baik dan tepat (dengan tidak membuang waktu, tenaga, biaya) [7].

Sedangkan menurut S.P.Hasibuan (1984; 233-4) efisiensi merupakan perbandingan yang terbaik antara sebuah input (masukan) dan output (hasil antara keuntungan dengan sumber-sumber yang dipergunakan), seperti halnya juga hasil optimal yang telah dicapai dengan penggunaan sumber yang terbatas. Jadi bisa dikatakan hubungan antara apa yang telah diselesaikan [8].

Kerja dalam Kamus Besar Bahasa Indonesia (KBBI) berarti:

1. kegiatan melakukan sesuatu; yang dilakukan (diperbuat)

2. sesuatu yang dilakukan untuk mencari nafkah; mata pencaharian

3. perayaan yang berhubungan dengan perkawinan, khitanan, dan sebagainya; pesta perjamuan [9].

\section{2 Metodologi Penelitian}

Metode penelitian yang digunakan penulis adalah metode kuantitaif yaitu metode penelitian yang menggunakan data berupa angka sebagai alat untuk menganalisis keterangan tentang apa yang ingin diketahui. [10].

Metode pengumpulan data yang digunakan oleh penulis adalah dengan menyebarkan kuesioner kepada 35 karyawan dengan jumlah 27 pertanyaan untuk mendapatkan data primer. Responden sebelumnya dipersempit dengan pembatasan masa kerja, dimana responden setidaknya sudah bekerja di PT. Asuransi Sinar Mas selama 1 tahun atau dianngap sudah mengetahui dan paham akan strategi knowledge management yang dijalankan di PT. Asuransi Sinar Mas. Setelah itu responden dipilih secara acak sehingga hasil yang didapatkan berasal dari berbagai divisi dan rentang usia yang berbeda.

Metode pengukuran yang digunakan untuk mengetahui tingkat kualitas sumber daya manusia adalah dengan strategi knowledge management dan menggabungkan faktor kualitas dari European Foundation for Quality Management (EFQM). Berikut adalah pemodelan dari metode pengukuran yang dimaksud (Syifa Nur Rakhmah:2017) [11]:
a. Strategi Kodifikasi $\longrightarrow$ Pendekatan Knowledge Management
1. Kebijakan dan Strategi (Policy \& Strategy) $\rightarrow$ EFQM.
2. Proses (Processes) $\longrightarrow$ EFQM.
3. Dampak terhadap lingkungan (Impact on Society) $\rightarrow$ EFQM.
4. Hasil bisnis (Business Result) $\rightarrow$ EFQM.
b. Strategi Personalisasi $\longrightarrow$ Pendekatan knowledge management
1. Kepemimpinan (Leadership) $\rightarrow$ EFQM.
2. Manajemen Manusia (People Management) $\rightarrow$ EFQM.
3. Sumber Daya (Resources) $\rightarrow$ EFQM.
4. Kepuasan Pengguna (Customer Satisfaction) $\rightarrow$ EFQM.
5. Kepuasan Karyawan (Employee Satisfaction) $\rightarrow$ EFQM.

Untuk mengukur tingkat pemahaman karyawan mengenai knowledge management yang berlaku di perusahaan dan seberapa berpengaruh knowledge management terhadap efisiensi kerja karyawan, penulis menggunakan Skala Likert dalam menggabungkan strategi knowledge management dengan EFQM. Skala Likert disesuaikan dengan kebutuhan penulis, dalam hal ini penulis menggunakan 5 poin yang dapat dirincikan pada tabel 2.1: 
Jatisi

ISSN 2407-4322

Vol. 7, No. 2, Agustus 2020, Hal. 338-348

E- ISSN 2503- 2933

Tabel 1. Skor Skala Likert

\begin{tabular}{c|c|c|}
\hline Skor & & Jawaban \\
\hline $\mathbf{5}$ & SS & Sangat Setuju \\
\hline $\mathbf{4}$ & S & Setuju \\
\hline $\mathbf{3}$ & N & Netral \\
\hline $\mathbf{2}$ & TS & Tidak Setuju \\
\hline $\mathbf{1}$ & STS & $\begin{array}{c}\text { Sangat Tidak } \\
\text { Setuju }\end{array}$ \\
\hline \multicolumn{2}{l}{ Sumber: Sugiyono $(2008 \cdot 38)$} \\
\hline
\end{tabular}

Sumber: Sugiyono (2008:38)

Tabel 2. Interval Skala Likert

\begin{tabular}{|l|l|}
\hline Interval & \multicolumn{1}{c}{ Keterangan } \\
\hline $4,20-5,00$ & Sangat Baik \\
\hline $3,40-4,19$ & Baik \\
\hline $2,60-3,39$ & Cukup Baik \\
\hline $1,80-2,59$ & Buruk \\
\hline $1,00-1,79$ & Sangat Buruk \\
\hline \multicolumn{2}{|c|}{ Sumber: Sugiyono (2008:38) }
\end{tabular}

\section{HASIL DAN PEMBAHASAN}

Berdasarkan hasil kuesioner yang disebarkan kepada 35 karyawan di PT. Asuransi Sinar Mas didapatkan hasil seperti pada tabel 3.

Tabel 3. Hasil Perhitungan Kuesioner Menggunakan Skala Likert

\begin{tabular}{|c|c|c|c|c|c|c|c|}
\hline Responden & SS & S & $\mathbf{N}$ & TS & STS & Total & $\begin{array}{c}\text { Rata- } \\
\text { rata }\end{array}$ \\
\hline 1 & 0 & 0 & 81 & 0 & 0 & 81 & 3 \\
\hline 2 & 0 & 72 & 15 & 8 & 0 & 95 & 3,52 \\
\hline 3 & 110 & 16 & 0 & 2 & 0 & 128 & 4,74 \\
\hline 4 & 10 & 60 & 30 & 0 & 0 & 100 & 3,70 \\
\hline 5 & 0 & 16 & 60 & 6 & 0 & 82 & 3,04 \\
\hline 6 & 5 & 48 & 42 & 0 & 0 & 95 & 3,52 \\
\hline 7 & 5 & 24 & 54 & 4 & 0 & 87 & 3,22 \\
\hline 8 & 20 & 44 & 36 & 0 & 0 & 100 & 3,70 \\
\hline 9 & 65 & 56 & 0 & 0 & 0 & 121 & 4,48 \\
\hline 10 & 10 & 80 & 15 & 0 & 0 & 105 & 3,89 \\
\hline 11 & 100 & 24 & 3 & 0 & 0 & 127 & 4,70 \\
\hline 12 & 40 & 56 & 15 & 0 & 0 & 111 & 4,11 \\
\hline 13 & 80 & 36 & 6 & 0 & 0 & 122 & 4,52 \\
\hline 14 & 25 & 56 & 24 & 0 & 0 & 105 & 3,89 \\
\hline 15 & 0 & 84 & 18 & 0 & 0 & 102 & 3,78 \\
\hline 16 & 0 & 20 & 57 & 6 & 0 & 83 & 3,07 \\
\hline 17 & 0 & 92 & 12 & 0 & 0 & 104 & 3,85 \\
\hline 18 & 0 & 60 & 36 & 0 & 0 & 96 & 3,56 \\
\hline 19 & 80 & 32 & 9 & 0 & 0 & 121 & 4,48 \\
\hline 20 & 40 & 76 & 0 & 0 & 0 & 116 & 4,30 \\
\hline 21 & 130 & 4 & 0 & 0 & 0 & 134 & 4,96 \\
\hline
\end{tabular}

Pakiding, et., al (Analisis Pengaruh Strategi Knowledge Management Terhadap Efisiensi Kerja Karyawan) 


\begin{tabular}{|c|c|c|c|c|c|c|c|}
\hline 22 & 0 & 88 & 15 & 0 & 0 & 103 & 3,81 \\
\hline 23 & 15 & 68 & 21 & 0 & 0 & 104 & 3,85 \\
\hline 24 & 10 & 80 & 15 & 0 & 0 & 105 & 3,89 \\
\hline 25 & 0 & 96 & 9 & 0 & 0 & 105 & 3,89 \\
\hline 26 & 10 & 48 & 33 & 0 & 2 & 93 & 3,44 \\
\hline 27 & 30 & 68 & 12 & 0 & 0 & 110 & 4,07 \\
\hline 28 & 15 & 48 & 24 & 6 & 1 & 94 & 3,48 \\
\hline 29 & 10 & 84 & 12 & 0 & 0 & 106 & 3,92 \\
\hline 30 & 0 & 108 & 0 & 0 & 0 & 108 & 4 \\
\hline 31 & 40 & 72 & 3 & 0 & 0 & 115 & 4,26 \\
\hline 32 & 0 & 32 & 54 & 2 & 0 & 88 & 3,26 \\
\hline 33 & 25 & 84 & 3 & 0 & 0 & 112 & 4,15 \\
\hline 34 & 10 & 44 & 33 & 6 & 0 & 93 & 3,44 \\
\hline 35 & 120 & 0 & 9 & 0 & 0 & 129 & 4,78 \\
\hline Total & $\mathbf{1 0 2 0}$ & $\mathbf{1 9 9 6}$ & $\mathbf{8 1 9}$ & $\mathbf{4 0}$ & $\mathbf{3}$ & $\mathbf{3 8 7 8}$ & $\mathbf{4 , 1 0}$ \\
\hline
\end{tabular}

Dari perhitungan yang dilakukan oleh penulis melalui pengumpulan data kepada 35 responden dan menggunakan skala likert maka hasil yang diperoleh adalah 4,10, dimana dengan hasil tersebut keterangan yang didapatkan adalah Baik. Kemudian untuk mengukur tingkat kualitas knowledge management di perusahaan PT. Asuransi Sinar Mas menggunakan rumus sebagai berikut (Sumber: Narimawati, 2007) [11]:

$\%$ s aktual $=\frac{\sum \text { s aktual }}{\sum \text { sideal }} \times 100 \%$

Keterangan:

- s: skor.

- Skor aktual adalah total jawaban sesungguhnya dari responden mengenai kuesioner yang telah diberikan.

- Skor ideal adalah total nilai tertinggi yang didapatkan jika semua responden menjawab sangat setuju.

Untuk mendeskripsikan kualitas knowledge management dari perhitungan rumus (1), penulis menggunakan tabel 3.2. kriteria persentase tanggapan responden sebagai acuan.

Tabel 4. Kriteria Persentase Tanggapan Responden untuk Strategi Knowledge Management

\begin{tabular}{|c|c|}
\hline \% Jumlah Skor & Keterangan \\
\hline $20,00 \%-36,00 \%$ & Tidak Baik \\
\hline $36,01 \%-52,00 \%$ & Kurang Baik \\
\hline $52,01 \%-68,00 \%$ & Cukup \\
\hline $68,01 \%-84,00 \%$ & Baik \\
\hline $84,01 \%-100 \%$ & Sangat Baik \\
\hline Sumber: Narimawati $(2007: 10)[11]$ \\
\hline
\end{tabular}

Kemudian untuk mendeskripsikan pengaruh knowledge management terhadap efisiensi kerja karyawan, penulis menggunakan tabel kriteria yang sama dengan tabel sebelumnya namun terdapat perubahan keterangan yang disesuaikan kembali dengan kebutuhan penulis. 
Tabel 5. Kriteria Persentase Tanggapan Responden untuk Strategi Knowledge Management

\begin{tabular}{c|c}
\hline \% Jumlah Skor & Keterangan \\
\hline $20,00 \%-36,00 \%$ & Tidak Berpengaruh \\
\hline $36,01 \%-52,00 \%$ & Kurang Berpengaruh \\
\hline $52,01 \%-68,00 \%$ & Cukup Berpengaruh \\
\hline $68,01 \%-84,00 \%$ & Berpengaruh \\
\hline $84,01 \%-100 \%$ & Sangat Berpengaruh \\
\hline
\end{tabular}

Sumber: Narimawati (2007:10) [11]

\section{A. Strategi Kodifikasi}

Berdasarkan pemodelan startegi knowledge management dengan menggabungkan faktor kualitas EFQM yang telah dijelaskan, maka beberapa faktor kualitas yang digunakan dalam startegi kodifikasi pada kuesioner adalah Kebijakan dan Startegi (Policy \& Strategy), Proses (Processes), Dampak terhadap Lingkungan (Impact on Society), dan Hasil Bisnis (Business Result). Tabel 3.4 berikut merupakan hasil kuesioner dari pertanyaan mengenai strategi kodifikasi.

Tabel 6. Hasil Perhitungan Kuesioner Strategi Kodifikasi

\begin{tabular}{|c|c|c|c|c|c|c|c|c|c|}
\hline \multicolumn{2}{|l|}{ Bobot } & 5 & 4 & 3 & 2 & 1 & \multirow[t]{2}{*}{ Responden } & \multirow{2}{*}{$\begin{array}{c}\text { Skor } \\
\text { aktual }\end{array}$} & \multirow{2}{*}{$\begin{array}{l}\text { Skor } \\
\text { ideal }\end{array}$} \\
\hline \multicolumn{2}{|l|}{ Hasil } & SS & $S$ & $\mathbf{N}$ & TS & STS & & & \\
\hline \multirow{2}{*}{$\begin{array}{l}\text { Kebijakan } \\
\text { \& strategi }\end{array}$} & 1 & 6 & 18 & 9 & 2 & 0 & 35 & 133 & 175 \\
\hline & 2 & 7 & 17 & 9 & 2 & 0 & 35 & 134 & 175 \\
\hline \multirow[t]{2}{*}{ Proses } & 3 & 10 & 19 & 6 & 0 & 0 & 35 & 144 & 175 \\
\hline & 4 & 7 & 19 & 9 & 0 & 0 & 35 & 138 & 175 \\
\hline \multirow{2}{*}{$\begin{array}{l}\text { Dampak } \\
\text { terhadap } \\
\text { lingkungan }\end{array}$} & 5 & 3 & 21 & 11 & 0 & 0 & 35 & 132 & 175 \\
\hline & 6 & 5 & 11 & 17 & 2 & 0 & 35 & 124 & 175 \\
\hline \multirow{2}{*}{$\begin{array}{l}\text { Hasil } \\
\text { bisnis }\end{array}$} & 7 & 9 & 20 & 6 & 0 & 0 & 35 & 143 & 175 \\
\hline & 8 & 6 & 20 & 9 & 0 & 0 & 35 & 137 & 175 \\
\hline \multicolumn{2}{|l|}{ Total } & 53 & 145 & 76 & 6 & 0 & & 1085 & 1400 \\
\hline
\end{tabular}

Dari Tabel 3.4 dapat diketahui bahwa skor aktual adalah 1085 dan skor ideal adalah 1400, sehingga dapat diketahui untuk \%skor aktual adalah:

$$
\begin{aligned}
\% \text { skor aktual } & =\frac{1085}{1400} \times 100 \% \\
& =77,5 \% \text { (Baik) }
\end{aligned}
$$

Berdasarkan hasil pengujian diatas, dapat diketahui bahwa \%skor aktual dari strategi kodifikasi adalah $77,5 \%$ atau dengan kata lain strategi kodefikasi dalam knowledge management sudah baik menurut responden.

\section{B. Strategi Personalisasi}

Setelah mengetahui kondisi penerapan knowledge management khususnya yang menggunakan staretgi kodifikasi, selanjutnya penulis akan menggabungkan strategi knowledge management dengan faktor kualitas EFQM untuk mengetahui kondisi strategi personalisasi. Beberapa faktor kualitas yang digunakan dalam startegi personalisasi pada kuesioner adalah 
Kepemimpinan (Leadership), Manajemen Manusia (People Management), Sumber Daya (Resources), Kepuasan Pengguna (Customer Satisfaction), dan Kepuasan Karyawan (Employee Satisfaction). Berikut ini merupakan hasil kuesioner dari pertanyaan mengenai strategi personalisasi.

Tabel 7. Hasil Perhitungan Kuesioner Strategi Personalisasi

\begin{tabular}{|c|c|c|c|c|c|c|c|c|c|}
\hline \multicolumn{2}{|l|}{ Bobot } & 5 & 4 & 3 & 2 & 1 & \multirow{2}{*}{ Responden } & \multirow{2}{*}{$\begin{array}{c}\text { Skor } \\
\text { aktual }\end{array}$} & \multirow{2}{*}{$\begin{array}{l}\text { Skor } \\
\text { ideal }\end{array}$} \\
\hline Hasil & & SS & $\mathbf{S}$ & $\mathbf{N}$ & TS & STS & & & \\
\hline \multirow{2}{*}{ Kepemimpinan } & 9 & 6 & 14 & 15 & 0 & 0 & 35 & 131 & 175 \\
\hline & 10 & 7 & 20 & 7 & 1 & 0 & 35 & 138 & 175 \\
\hline \multirow{2}{*}{$\begin{array}{l}\text { Manajemen } \\
\text { manusia }\end{array}$} & 11 & 7 & 19 & 8 & 1 & 0 & 35 & 137 & 175 \\
\hline & 12 & 10 & 7 & 12 & 4 & 2 & 35 & 124 & 175 \\
\hline \multirow{2}{*}{ Sumber daya } & 13 & 7 & 17 & 11 & 0 & 0 & 35 & 136 & 175 \\
\hline & 14 & 7 & 18 & 10 & 0 & 0 & 35 & 137 & 175 \\
\hline \multirow{2}{*}{$\begin{array}{l}\text { Kepuasan } \\
\text { pengguna }\end{array}$} & 15 & 7 & 19 & 9 & 0 & 0 & 35 & 138 & 175 \\
\hline & 16 & 14 & 18 & 3 & 0 & 0 & 35 & 151 & 175 \\
\hline \multirow{2}{*}{$\begin{array}{l}\text { Kepuasan } \\
\text { karyawan }\end{array}$} & 17 & 8 & 19 & 8 & 0 & 0 & 35 & 140 & 175 \\
\hline & 18 & 9 & 18 & 7 & 1 & 0 & 35 & 140 & 175 \\
\hline \multicolumn{2}{|l|}{ Total } & 82 & 169 & $\begin{array}{l}9 \\
0\end{array}$ & 7 & 2 & & 1372 & 1750 \\
\hline
\end{tabular}

Dari Tabel 3.5 dapat diketahui bahwa skor aktual adalah 1372 dan skor ideal adalah 1750, sehingga dapat diketahui untuk \%skor aktual adalah:

$$
\begin{aligned}
\% \text { skor aktual } & =\frac{1372}{1750} \times 100 \% \\
& =78,4 \% \text { (Baik) }
\end{aligned}
$$

Berdasarkan hasil pengujian diatas, dapat diketahui bahwa \%skor aktual dari strategi personalisasi adalah $78,4 \%$ atau dengan kata lain strategi kodefikasi dalam knowledge management sudah baik menurut responden.

Berdasarkan hasil pengujian kualitas strategi kodifikasi dan strategi personalisasi, berikut merupakan rekapitulasi dari kedua strategi:

Tabel 8. Hasil Perhitungan Rekapitulasi Strategi Kodifikasi dan Personalisasi.

\begin{tabular}{|l|c|c|c|c|}
\hline \multicolumn{1}{|c|}{ Aspek } & $\begin{array}{c}\text { Skor } \\
\text { aktual }\end{array}$ & $\begin{array}{c}\text { Skor } \\
\text { ideal }\end{array}$ & $\begin{array}{c}\text { \%Skor } \\
\text { aktual }\end{array}$ & Hasil \\
\hline $\begin{array}{l}\text { Strategi } \\
\text { kodifikasi }\end{array}$ & 1085 & 1400 & 77,5 & Baik \\
\hline $\begin{array}{l}\text { Strategi } \\
\text { personalisasi }\end{array}$ & 1372 & 1750 & 78,4 & Baik \\
\hline Total & $\mathbf{2 4 5 7}$ & $\mathbf{3 1 5 0}$ & $\mathbf{7 7 , 9}$ & Baik \\
\hline
\end{tabular}

Dari Tabel 3.6 dapat diketahui bahwa kualitas penerapan strategi knowledge management di PT. Asuransi Sinar Mas secara keseluruuhan sudah baik dengan persentase $77,9 \%$. 


\section{Pengaruh Strategi Knowledge Management terhadap Efisiensi Kerja Karyawan}

Setelah mengetahui seberapa baik kondisi penerapan knowledge management pada perusahaan PT. Asuransi Sinar Mas, maka penulis akan mengidentifikasi seberapa besar pengaruh knowledge management terhadap efisiensi kerja karyawan.

Berikut ini merupakan hasil kuesioner dari pertanyaan mengenai pengaruh strategi knowledge management terhadap efisiensi kerja karyawan yang diterapkan di PT. Asuransi Sinar Mas.

Tabel 9. Hasil Perhitungan Kuesioner Pengaruh Strategi Knowledge Management

Terhadap Efisiensi Kerja Karyawan

\begin{tabular}{|c|c|c|c|c|c|c|c|c|c|}
\hline \multirow{2}{*}{\multicolumn{2}{|c|}{$\begin{array}{l}\text { Bobot } \\
\text { Hasil }\end{array}$}} & 5 & 4 & 3 & 2 & 1 & \multirow{3}{*}{$\begin{array}{c}\text { Responden } \\
35\end{array}$} & \multirow{3}{*}{$\begin{array}{c}\begin{array}{c}\text { Skor } \\
\text { aktual }\end{array} \\
127\end{array}$} & \multirow{3}{*}{$\begin{array}{r}\begin{array}{r}\text { Skor } \\
\text { ideal }\end{array} \\
175\end{array}$} \\
\hline & & SS & $\mathbf{S}$ & $\mathbf{N}$ & TS & STS & & & \\
\hline $\begin{array}{l}\text { Kebijakan \& } \\
\text { strategi }\end{array}$ & 19 & 5 & 15 & 13 & 1 & 1 & & & \\
\hline Proses & 20 & 4 & 16 & 14 & 1 & 0 & 35 & 128 & 175 \\
\hline $\begin{array}{l}\text { Dampak } \\
\text { terhadap } \\
\text { lingkungan }\end{array}$ & 21 & 7 & 19 & 9 & 0 & 0 & 35 & 138 & 175 \\
\hline Hasil bisnis & 22 & 7 & 19 & 8 & 1 & 0 & 35 & 137 & 175 \\
\hline Kepemimpinan & 23 & 9 & 19 & 6 & 1 & 0 & 35 & 141 & 175 \\
\hline $\begin{array}{l}\text { Manajemen } \\
\text { manusia }\end{array}$ & 24 & 8 & 16 & 10 & 1 & 0 & 35 & 136 & 175 \\
\hline Sumber daya & 25 & 7 & 14 & 13 & 1 & 0 & 35 & 132 & 175 \\
\hline $\begin{array}{l}\text { Kepuasan } \\
\text { pengguna }\end{array}$ & 26 & 8 & 16 & 10 & 1 & 0 & 35 & 136 & 175 \\
\hline $\begin{array}{l}\text { Kepuasan } \\
\text { karyawan }\end{array}$ & 27 & 11 & 21 & 3 & 0 & 0 & 35 & 148 & 175 \\
\hline Total & & 66 & 155 & 86 & 7 & 1 & & 1223 & 1575 \\
\hline
\end{tabular}

Dari Tabel 3.6 dapat diketahui bahwa skor aktual adalah 1223 dan skor ideal adalah 1575 , sehingga dapat diketahui untuk \%skor aktual adalah:

$$
\begin{aligned}
\% \text { skor aktual } & =\frac{1223}{1575} \times 100 \%(4) \\
& =77,6 \% \text { (Berpengaruh) }
\end{aligned}
$$

Berdasarkan hasil pengujian diatas, dapat diketahui bahwa \%skor aktual dari pengaruh stretgi knowledge management terhadap efisiensi kerja karyawan adalah 77,6\% atau dengan kata lain tingkat pengaruhnya adalah berpengaruh menurut responden dalam hal ini karyawan itu sendiri.

\section{KESIMPULAN}

Pada penelitian ini dilakukan pengujian mengenai pengaruh strategi knowledge management terhadap efisiensi kerja karyawan di PT. Asuransi Sinar Mas. Terdapat beberapa hal yang dapat disimpulkan berdasarkan perhitungan yang dilakukan menggunakan skala likert pada bab sebelumnya. 
Beberapa hal yang dapat disimpulkan yaitu dalam penerapan strategi knowledge management di PT. Asuransi Sinar Mas, pengujian kualitas berdasarkan persentase skor aktual menunjukkan hasil sudah baik dengan persentase yang didapat sebesar 77,9\% dengan uraian untuk strategi kodifikasi mendapatkan persentase 77,5\% (baik) dan strategi personifikasi 78,4\% (baik). Selain itu terdapat pengaruh antara strategi knowledge management dengan efisiensi kerja yang dirasakan oleh karyawan. Pada hasil pengujian tingkat pengaruh strategi knowledge management terhadap efisiensi kerja karyawan berdasarkan persentase skor aktual menunjukkan berpengaruh dengan persentase yang didapatkan sebesar 77,6\%.

\section{SARAN}

Adapun saran yang dapat diberikan oleh penulis berdasarkan kesimpulan yang didapatkan adalah:

1. Perusahaan perlu mengimbangi antara strategi kodifikasi yang dapat berupa prosedur kerja yang baik dengan strategi personalisasi yang dapat berupa pengetahuan personal yang didapatkan dari sharing antar karyawan.

2. Perusahaan diharapkan untuk lebih memperhatikan dampak yang dapat diberikan kepada lingkungan sekitar dan strategi dalam manajemen manusia, dikarenakan skor aktual yang didapatkan merupakan skor terendah dari keseluruhan skor aktual.

3. Jumlah sampel yang digunakan penulis dalam penelitian ini yaitu sebanyak 35 responden, jumlah ini masih relatif sedikit. Diharapkan dalam penelitian selanjutnya, penulis dapat menambah jumlah sampel agar mendapatkan hasil penelitian yang lebih baik.

\section{UCAPAN TERIMA KASIH}

Penulis mengucapkan terima kasih kepada Tuhan Yang Maha Esa karena atas penyertaan-Nya sehingga penulis dapat menyelesaikan jurnal ini. Penulis juga mengucapkan terima kasih kepada keluarga dan teman-teman terdekat yang sudah memberikan dukungan kepada penulis.

\section{DAFTAR PUSTAKA}

[1] M. Fermilia, D. Taufiq, and W. Laksmono, 2016, "Penerapan Manajemen Pengetahuan Di Bapeten Sebagai Implementasi Dari Amanah Reformasi Birokrasi,” pp. 1-5.

[2] R. . Sandi, "Pentingnya Knowledge Management dalam Perusahaan," 2019. https://sis.binus.ac.id/2019/06/26/pentingnya-knowledge-management-dalamperusahaan/ (accessed Jul. 20, 2020).

[3] D. P. Wijayanti and D. Sundiman, 2017, "Pengaruh Knowledge Management Terhadap Kinerja Karyawan ( Studi Empiris Pada Pt. Sms Kabupaten Kotawaringin Timur)," DeReMa J. Manaj., Vol. 12, No. 1, pp. 69-85.

[4] A. M. Caroline and Haryanto, 2015. "Pengaruh Modal Intelektual Terhadap Profitabilitas Perusahaan (Studi Empiris Pada Perusahaan Manufaktur Yang Terdaftar 
Di Bursa Efek Indonesia Tahun 2011-2013)," Diponegoro J. Account., Vol. 4, No. 3, pp. 309-318,

[5] "Visi dan Misi PT. Asuransi Sinar Mas. 2020," https://www.sinarmas.co.id/tentangkami/visi-dan-misi (accessed Mar. 10).

[6] E. S. Utomo, 2016, "Pengaruh Tacit Knowledge Dan Explicit Knowledge Terhadap Kinerja Karyawan Pt Wadja Karya Dunia Pati."

[7] "Arti kata efisiensi - Kamus Besar Bahasa Indonesia (KBBI) Online." 2020, https://kbbi.kemdikbud.go.id/entri/efisiensi (accessed Mar. 10, 2020).

[8] Tommy, "Pengertian Efisiensi Menurut Para Ahli," 2019. https://kotakpintar.com/pengertian-efisiensi-menurut-para-ahli/ (accessed Jan. 11, 2020).

[9] "Arti kata kerja - Kamus Besar Bahasa Indonesia (KBBI) Online." 2020, https://kbbi.kemdikbud.go.id/entri/kerja (accessed Mar. 10, 2020).

[10] R. Hayati, 2019. "Pengertian Penelitian Kuantitatif, Macam, Ciri, dan Cara Menuliskannya," https://penelitianilmiah.com/penelitian-kuantitatif/ (accessed Jan. 11, 2020).

[11] S. N. Rakhmah, 2017. "Strategi Knowledge Management Untuk Meningkatkan Pengetahuan Berdasarkan Knowledge-Based Organizational Model (Studi Kasus PT Telekomunikasi Indonesia Jakarta)," Inf. Syst. Educ. Prof, Vol. 1, No. 2, pp. 115-124. 